\title{
Hydrological modelling for river basin management in a highly hydro-geological conditioned environment
}

\author{
D. Guida, A. Longobardi \& P. Villani \\ Department of Civil Engineering, University of Salerno, Italy
}

\begin{abstract}
Water resources management represents a present key issue in hydrology, and hydrological models generating streamflow time series are useful tools in this field. It is possible to refer, in the extreme, to lumped or fully distributed approaches, but when river basins with particular features have to be modeled it is possible to take advantage of a semi-distributed formulation. In this study we propose a semi-distributed conceptually based modeling approach, supported by field measurements collected within several seasonal campaigns, that has been set up for the Bussento river basin, located in southern Italy, characterized by soils and rocks with highly different hydraulic permeability and above all a highly hydro-geological conditioning. The proposed approach, which joins together all hydraulic, hydrological and geological data, is able to reproduce the river discharge mean characteristic.

Keywords: rainfall-runoff model, water resources management, hydrogeological conditioning.
\end{abstract}

\section{Introduction}

Water resources management, more and more limited and poor in quality, represents a present key issue in hydrology. The development of a community is highly related to the management of the water resources available for the community itself and there is a need, for this reason, to rationalize the existing resources, to plan water resources use, to preserve water quality and, on the other had, to prevent flood risk.

From this point of view, hydrological models, generating streamflow time series which are statistically equivalent to the observed streamflow time series, 
become useful tools. When river basins with particular features have to be modeled, both traditionally conceptually based models and more recent sophisticated distributed models appear to give not very reliable results. In those cases it is possible to take advantage of a semi-distributed formulation, where every sub-catchment is modeled to account for its features and information coming from all the sub-catchments are related to each other in order to improve the system description.

In this study we propose a semi-distributed conceptually based modeling approach, supported by field measurements collected within several seasonal campaigns, spanning over two years, that has been set up for the Bussento river basin, located in southern Italy, well know to hydrogeology and geomorphology scientists for its karst features, characterized by soils and rocks with highly different hydraulic permeability and above all an highly hydrogeological conditioning. The groundwater circulation is very complex, as it will be later discussed and frequently groundwater inflows from the outside of the hydrological watershed and groundwater outflows toward surrounding drainage systems occur. Even though the proposed approach has some similarity with a few well known conceptually schemes, based on the existence of linear reservoirs and liner channel to describe the different components the streamflow can be decomposed in, it is valuable because of the possibility, which is in this case the necessity, to join all together hydraulic, hydrological and geological data to achieve reliable results.

\section{The Bussento river basin geomorphological and hydro- geological features}

The Bussento River drainage basin, located in southern Italy, Campania Region, within the Cilento and Vallo di Diano National Park, is well know to geomorphologist and hydro-geologist for its widely and deeply karst features, as summit highland with dolines and poljes, lowland with blind valleys, disappearing streams into sinkholes, cave systems, and karst-induced groundwater aquifers. The main stream originates from Mount Cervati springs $(1888 \mathrm{~m})$, one of the highest mountain ridge in the Southern Apennine, then it flows downstream carving steep gorges and rapids, where further springs, along the streambed, increase the river discharge. The upper right area is characterize by marly-arenaceous rocks outcrop (M.nt Marchese hilly ridge), while the left upper area is characterized by limestone sequences (M.nt Rotondo highland and Serra Forcella). Further down, the Bussento river flows into "La Rupe "sinkhole channelling the surface flow into karst cave system and emerging four kilometers downstream, close to Morigerati town, at "Grotta Inferiore del Bussento". A few hundred meters downstream, the Bussento river merges with the Bussentino creek, originating from eastern sectors of the drainage basin, flowing along canyons and deep gorges carved into Meso-cenozoic limestone sequences.

In the western and southern sectors of the basin (Sciarapotamo creek subbasin), marly-argillaceous successions of the Liguride and "affinità sicilide" Complex (Bonardi G. [5]) dominate the hilly landscape, whereas they underlie 
the arenaceous-conglomerate sequences (Guida et al. [6]) at M.nt Centaurino (1511 m).

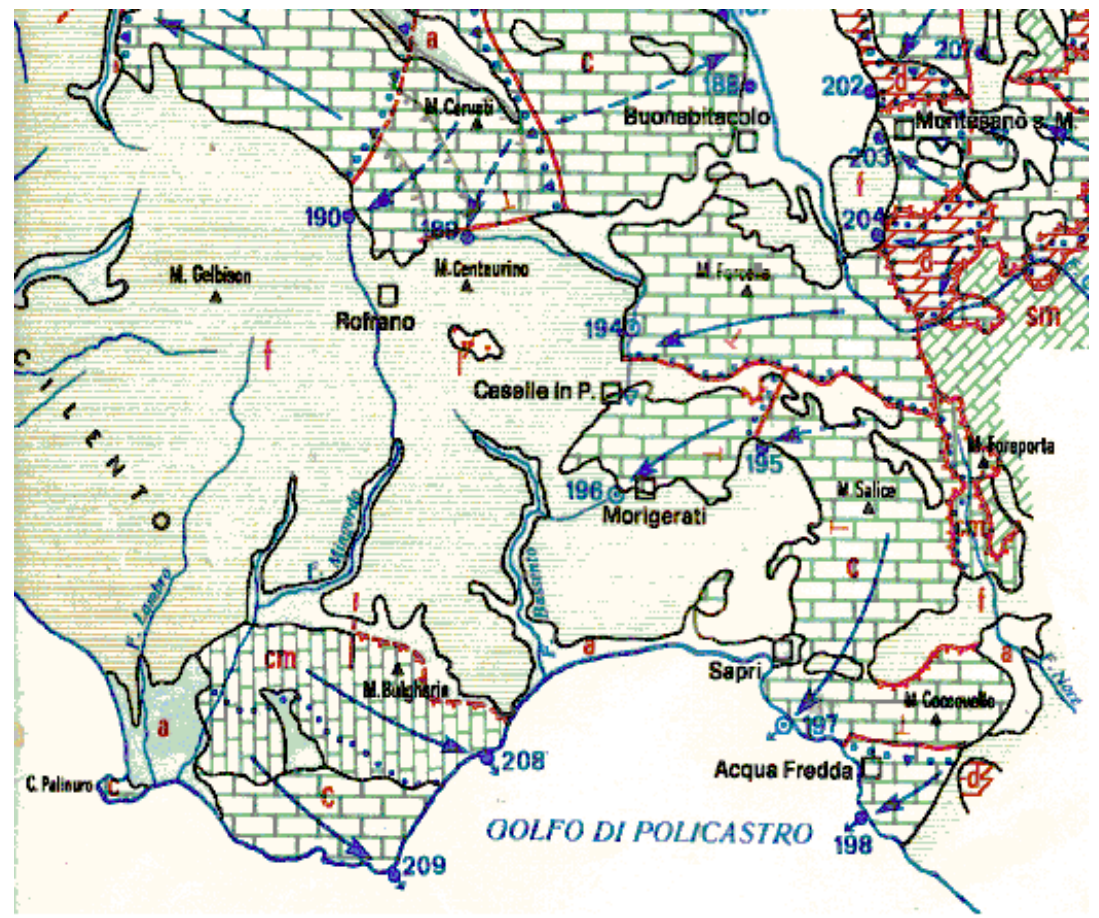

Figure 1: Hydro-geological scheme of the region (Celico [2]).

Based on the previous comments and given the presence of a complex hydroelectric system, the Bussento river basin cannot be considered a simple drainage basin, but a very complex Hydro-geological System (BHS). A number of homogeneous hydro-geological sectors can be recognized and outlined within it (figure 1).

\section{Conceptual hydro-geological modelling}

Because of the hydrogeological complexity of the BHS previously presented, a water deep circulation conceptual model has to be outlined before any hydrological computer-aided model can be built. The conceptual model is a preliminary physical-based model, accounting for an interconnected sequence of geologic substrates, permeability distribution, recharge areas and discharge points, that collectively provide a physical scheme of the recharge system, the storage system and the routing system.

Karst aquifers modelling is not an easy task. Anderson and Woessner [3] indicate "karst" as one of the advanced topics in the groundwater researches, and summarize a few attempted models, none of which produces reliable results. One 
of the earliest attempt of karst aquifers conceptualization (White [9]) focused on the variety of geologic settings and their controlling influence on groundwater flow patterns. This scheme was later expanded (White [11]) to take into account the overall area of the groundwater system. Based only on the type of permeability, Shuster and White [8] divided aquifers into "conduit flow" aquifers, which contain well developed conduit systems, and "diffuse flow" aquifers which do not. Following White [10], the basic components of the generic karst aquifer flow system can be sketched as in figure 3. Clearly, not all of these components are present in all aquifers, and their presence and relative importance is a fundamental point of distinguishing one aquifer from another. With reference to Iaccarino et al. [7] and White [10], this general conceptual model has been applied to the Bussento Hydro-geological System (BHS), recognizing the following recharge-discharge components (figure 2).

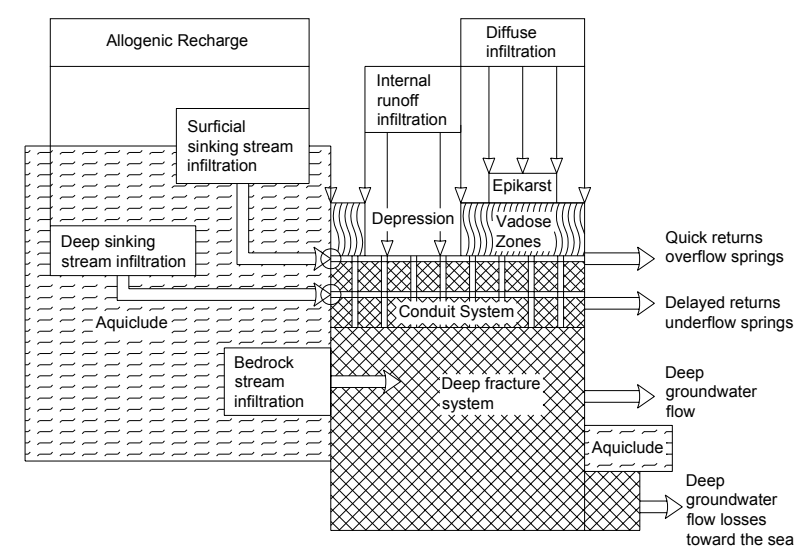

Figure 2: Specific conceptual model of the karst aquifers in the Bussento Hydrological System (BHS).

Four sources of recharge for karst aquifers can be recognized: i) allogenic recharge: as surface water collected on outside aquifer basin and injected into the aquifer via sinking streams developed on surrounding aquiclude; ii) internal runoff recharge: as overland flow comes into closed depressions (dolines and poljes) where it enters the aquifer through sinkhole drainage; iii) diffuse infiltration recharge: as precipitation on the land surface, where it infiltrates through the soil and rock, remaining for days or weeks in the vadose epikarst zone, before it migrates downward, through the rock fractures, into the percolation zone, finally reaching the water table into the saturation zone; iv) recharge from fractured bedrock streams: as perched groundwater systems above carbonate aquifers, in which water reaches the main aquifer by means of vadose shafts and open fracture systems along the margins of the perched aquifers and carbonate fractured bedrock streams. A distinguishing feature of Bussento karst 
aquifers is that most of the groundwater is discharged through a small number of large springs.

Figure 3 illustrate a simplified scheme of the Bussento river network indicating, on a planimetric point of view, the complex interaction between the diffuse springs system, which generally determine an increase in river discharge, and the hydroelectric system, i.e. the anthropic impact, which generally determine a decrease in river discharge, retained and diverted within dams, artificial lake and weirs for human water uses.

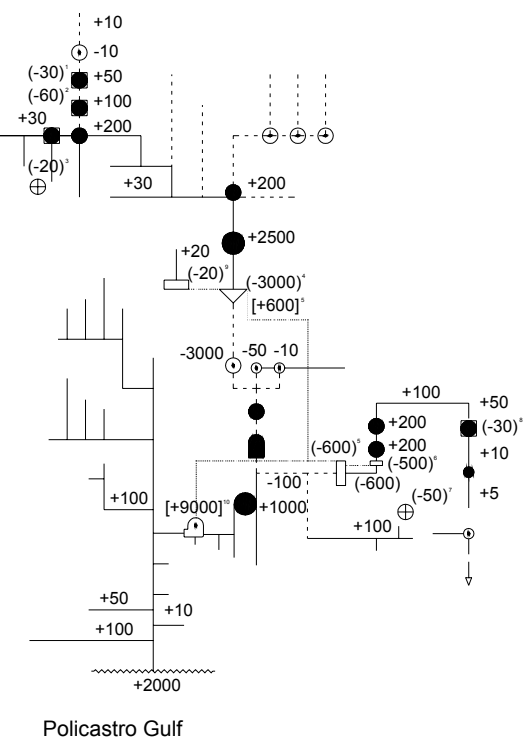

Figure 3: Bussento river network and interactions with the springs system and the hydroelectric system.

\section{Semi-distributed coupled hydro-geological and hydrological modelling}

\subsection{The monitoring campaigns}

Currently no working river flow discharge measurement stations are present over the catchment. Two stations were actually working, for a short period, over the decade 1960-1970, thus very short streamflow time series are indeed available. For this reason, on January 2003 the Regional Water Basin Authority, Sinistra Sele, started a monitoring campaign with the aim of measure in many different sections and on a monthly time scale the Bussento river discharge. Based on the Bussento catchment $\left(313 \mathrm{~km}^{2}\right)$ geomorphological and hydro-geological features described in the previous paragraphs, 13 stations were indicated as significant to individuate the river regime (figure 4). The monitoring campaigns is currently in progress managed by CUGRI, but so far only a two years periods has been 
analyzed. In the following paragraphs some results relative to collected data analysis, particularly referring to modelling applications, are given.

\subsection{Data analysis and modelling results}

Given the Bussento catchment geomorphological and hydro-geological features described in the previous paragraphs, a lumped model cannot guarantee reliable results. For this reason and taking advantage of the dense monitoring campaign, a semi-distributed formulation, accounting for each sub-basin particular characteristics, seems to be more appropriate.

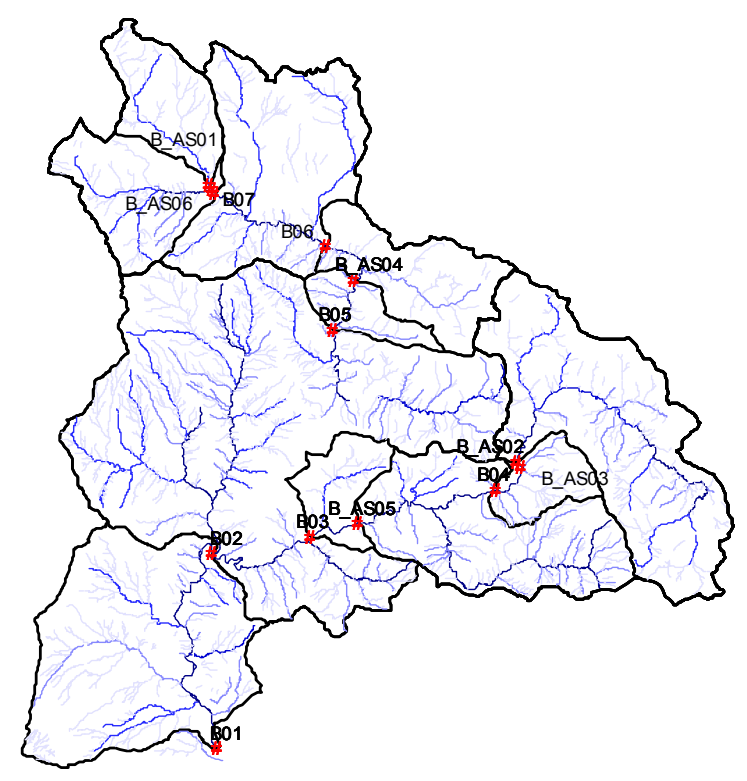

Figure 4: The Bussento river basin monitoring network.

When dealing with the monthly time scale each sub-basin can be described (figure 5) as two linear reservoirs in parallel, representing the groundwater flow and the deep subsurface flow, whereas the rainfall contributes which are characterized by delay times smaller then a month are supposed to reach the outlet through a linear channel (Claps et al. [1]). The scheme is also supported by the conceptual hydro-geological model described in the previous paragraph. In this case coupling the linear reservoirs balance equations with the whole system balance equation, total streamflow $\mathrm{D}$ at each time step is related to the net input by means of an ARMA $(2,2)$ model, which stochastic formulations corresponds to:

$$
D(t)-\Phi_{1} D(t-1)-\Phi_{2} D(t-2)=\varepsilon(t)-\Theta_{1} \varepsilon(t-1)+\Theta_{2} \varepsilon(t-2)
$$


where $\varepsilon$ is the model residual, related to the net input $\mathrm{I}$, that is then a periodic independent random process, and $\Phi_{1}, \Phi_{2}, \Theta_{1}$, and $\Theta_{2}$ are the model stochastic parameters, related to the model conceptual parameters $\mathrm{K}_{1}, \mathrm{~K}_{2}$ (reservoirs response times), $a$ and $b$ (recharge coefficients).

In its original formulation the model algorithm, starting from an observed streamflow time series, estimates the model parameters and, because of the univariate approach, with an inverse procedure, the net rainfall input.

Collected streamflow data consist of mean monthly values, measured at each section, over two years. These are not enough to run the $\operatorname{ARMA}(2,2)$ model with its inverse procedure.

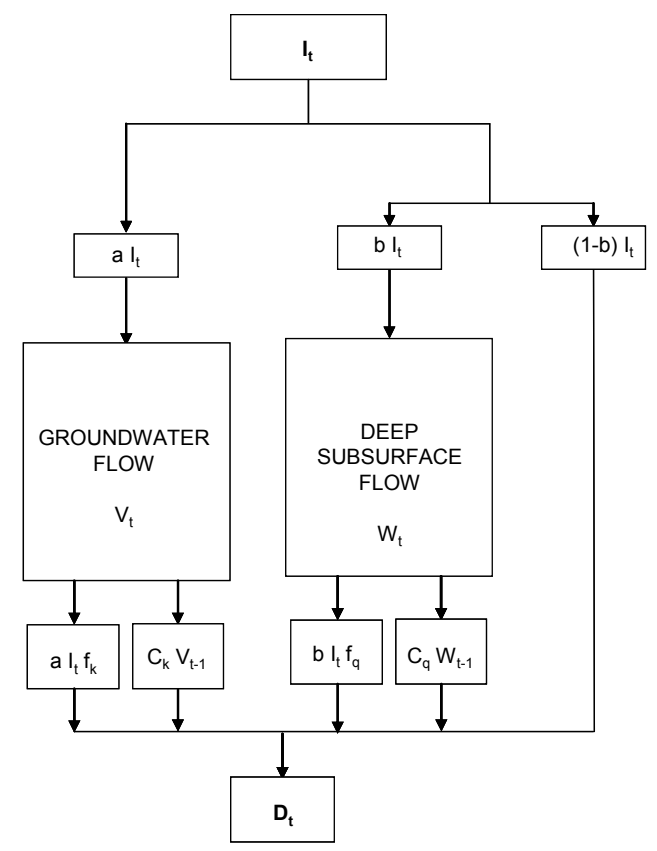

Figure 5: Linear system of monthly streamflow time series.

To set up a modelling approach able to reproduce observed discharge values, we estimated a priori model parameters and net rainfall input. Equation (1) as been then used to generate 1000 years monthly streamflow time series at each section, comparing thus the discharge probability distributions, at each section and for each month, with the occurred values.

The response times have been evaluated from streamflow collected data, applying the base flow recession equation:

$$
Q(t)=Q_{0} e^{-t / K}
$$

whereas the recharge coefficients corresponding to each section, i.e. the outlet of a sub-basin, have been initially assigned on the basis of the relative sub-basin 
hydrological and hydro-geological features and successively modified, with an iterative procedure, to achieve the better model results (table 1).

Table 1: $\quad$ Model parameters, response times and recharge coefficients.

\begin{tabular}{|l|c|c|c|c|}
\hline Section & $K_{1}$ (days) & $K_{2}$ (days) & $\mathrm{a}$ & $1-\mathrm{a}$ \\
\hline B_AS 05 & - & 11.07 & 0.00 & 1.00 \\
\hline B 04** & 149.71 & 7.37 & 0.70 & 0.30 \\
\hline B 04 & 153.66 & 119.75 & 0.70 & 0.30 \\
\hline B_AS 03 & 211.12 & 10.16 & 0.70 & 0.30 \\
\hline B_AS 02 & 81.21 & 25.42 & 0.30 & 0.70 \\
\hline B 01 & 280.94 & 31.12 & 0.60 & 0.40 \\
\hline B 02 & 280.00 & 32.61 & 0.70 & 0.30 \\
\hline B 03 & 293.69 & 46.62 & 0.80 & 0.20 \\
\hline B_AS 04 & 108.36 & 30.51 & 0.70 & 0.30 \\
\hline B 06 & 86.12 & 35.77 & 0.70 & 0.30 \\
\hline B 07 & 75.11 & 18.69 & 0.20 & 0.80 \\
\hline B_AS 01 & - & 30.07 & 0.00 & 1.00 \\
\hline B_AS 06 & 301.36 & - & 1.00 & 0.00 \\
\hline
\end{tabular}

With regard to the model rainfall net input, the procedure we pursued was to generate it from its probability density distribution, with given parameters. The $\mathrm{I}(\mathrm{t})$ probabilistic representation is the Bessel distribution, which is the sum of a Poissonian number of events with exponentially distributed intensity:

$$
\begin{array}{ll}
P[I=0]=e^{-\nu} & I=0 \\
f_{I}(I)=e^{-\lambda I-\nu}(\nu \lambda / I) \mathfrak{I}_{1}\left[2(\nu \lambda I)^{I / 2}\right] & I>0
\end{array}
$$

where $\lambda=1 / \beta$ is the exponential parameter, $v$ is the Poisson parameter and $\mathfrak{J}_{I}(x)$ is the modified Bessel function of order 1. The rationale for such probabilistic representation is given by the positive values and finite probability at zero that $\mathrm{I}(\mathrm{t})$ has to present.

Parameters $\beta$ and $v$ are estimated from the existing two streamflow time series. The temporal patterns found for the two series are rather similar, thus we assumed $\beta$ and $v$ spatially invariant over the catchment (table 2 ).

Table 2: $\quad$ Net rainfall input distribution $\beta$ and $v$ parameters.

\begin{tabular}{|c|c|c|c|c|c|c|c|c|c|c|c|c|}
\cline { 2 - 12 } \multicolumn{1}{c|}{} & Jan & Feb & Mar & Apr & May & Jun & Jul & Aug & Sep & Oct & Nov & Dec \\
\hline $\mathrm{u}$ & 1.05 & 1.19 & 1.21 & 1.39 & 1.48 & 1.82 & 2.07 & 1.66 & 1.28 & 1.09 & 1.04 & 1.03 \\
\hline$\beta$ & 5.29 & 2.65 & 1.52 & 1.43 & 6.33 & 0.73 & 0.30 & 0.86 & 2.85 & 2.69 & 1.77 & 3.63 \\
\hline
\end{tabular}


Figure 6 shows, as an example, the generated streamflow probability distribution, at section B07 for august. Measured values during august 2003 and august 2004 correspond respectively to the 55 percentile and to the 98 percentile. Model performance in 2004 is generally poor because of particular climatic conditions occurred in that year.

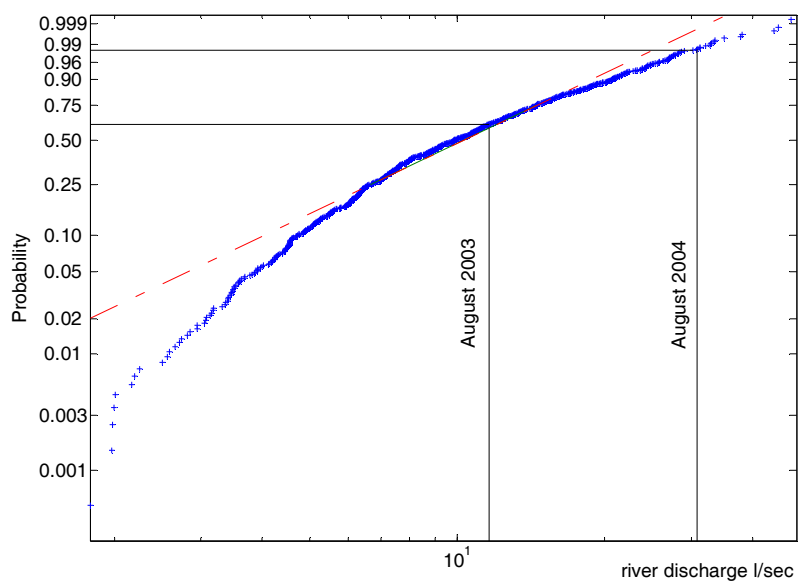

Figure 6: Generated streamflow probability distribution compared with occurred values over two years.

Similar results have been found at the remaining sections, with model adequacy being affected by the degree of anthropic impact and hydro-geological conditioning over the corresponding sub-basin.

\section{Conclusion}

In this paper we highlight the modeling difficulties that have to be faced when basin with particular features have to be investigated. The case study is the Bussento river basin, located in southern Italy, which is well know to hydrogeology and geomorphology scientists for its karst features, characterized by soils and rocks with highly different hydraulic permeability and above all an highly hydrogeological conditioning. In this case, a lumped methodology cannot guarantee satisfactory results but a semi-distributed formulation can be more appropriate. The methodology we have presented has some similarity with a few well known conceptually schemes, based on the existence of linear reservoirs and liner channel to describe the different components the streamflow can be decomposed in, but it join all together hydraulic, hydrological and geological data. In particular, the hydro-geological catchment's features have been used to drive the identification of the monitoring sections, i.e. the extension of each subbasin, and to assign a priori model parameters. Overall, the proposed modeling approach has a good performance, even though it appears in some sections inadequate, acknowledging the poor available database and the complexity of the system we have tried to model. 


\section{Acknowledgements}

The authors wish to thank the Regional Water Basin Authority, Sinistra Sele, and the CUGRI, Centro Universitario per la Previsione e Prevenzione dei Grandi Rischi, for their support. The research was partially supported by MIUR and MURST grant.

\section{References}

[1] Claps, P., Rossi, F. \& Vitale, C., Conceptual- stochastic modelling of seasonal runoff using autoregressive moving average models at different scales of aggregation. Water Resources Research, 29(8), pp. 2545-2559, 1993.

[2] Celico, P. B., Schema idrogeologico dell'Appennino Meridionale; Mem e Note Ist. Geol. Appl., 19 Napoli, 1978.

[3] Anderson, M.P. \& Woessner, W.W., Applied Ground Water Modelling. Academic Press, San Diego, 1992.

[4] Bonardi, G., Ciampo, G. \& Perrone, V., La formazione di Albidona nell'Appennino calabro-lucano: ulteriori dati stratigrafici e relazioni con le unità esterne appenniniche. Boll. Soc. Geologica Italiana, 104, Roma , 1985.

[5] Bonardi, G., Ciampo, G. \& Perrone, V., La formazione di Albidona nell'Appennino calabro-lucano: ulteriori dati stratigrafici e relazioni con le unità esterne appenniniche. Boll. Soc. Geologica Italiana, 104, Roma , 1988.

[6] Guida, D., Iaccarino, G. \& Perrone, V., Nuovi dati sulla successione del Flysch del Cilento nell'area di M.te Centaurino: relazioni fra Unità Litostratigrafiche, Unità Litotecniche e principali Sistemi Franosi”. Mem. Soc. Geol., 41, 1988.

[7] Iaccarino, G., Guida, D. \& Basso, C., Caratteristiche idrogeologiche della struttura carbonatica di Morigerati. Mem. Soc. Geologica Italiana, 41, 1065-1077, Roma, 1988.

[8] Shuster, E., T. \& White, W., B., Seasonal fluctuations in the chemistry of limestone springs. A possible means for characterizing carbonate acquifers. J. of Hydrology, 14, 93-128, 1971.

[9] White, W. B., Conceptual models for limestone acquifers. Groundwater, 7 (3), 15-21, 1969.

[10] White, W. B., Conceptual model for karstic acquifers. Speleogenesis and Karstic Aquifers - The virtual Scientifical Journal, 1, 1-6, 2002.

[11] White, W. B., Conceptual models for carbonatee acquifers: revised. In Dilamarter, R. R. and Casallany, S. C. (Eds): Hydrologic Problems in Karst Terrain. Western Kentucky University, Bowling Green, KY, 176$187,1977$.

[12] White, W. B., Conceptual model for karstic acquifers. Speleogenesis and Karstic Aquifers - The virtual Scientifical Journal, 1, 1-6, 2003. 